\title{
Oxygen Defect-Mediated Magnetism in Fe-C Codoped $\mathrm{TiO}_{2}$
}

\author{
Zhaorui Zou, ${ }^{1,2}$ Zhongpo Zhou, ${ }^{1,2,3}$ Haiying Wang, ${ }^{1,2}$ and Meng Du ${ }^{1,2}$ \\ ${ }^{1}$ College of Physics and Material Science, Henan Normal University, Xinxiang 453007, China \\ ${ }^{2}$ Henan Key Laboratory of Photovoltaic Materials, Xinxiang 453007, China \\ ${ }^{3}$ Key Laboratory of Artificial Micro- and Nanostructures of Ministry of Education and School of Physics and Technology, \\ Wuhan University, Wuhan 430072, China \\ Correspondence should be addressed to Zhongpo Zhou; paul@whu.edu.cn and Haiying Wang; wanghaiy@whu.edu.cn
}

Received 11 June 2016; Revised 15 August 2016; Accepted 24 August 2016

Academic Editor: Pavel Lejcek

Copyright ( 2016 Zhaorui Zou et al. This is an open access article distributed under the Creative Commons Attribution License, which permits unrestricted use, distribution, and reproduction in any medium, provided the original work is properly cited.

The magnetic properties of the $\mathrm{C}$ doped and $\mathrm{C}$-Fe codoped $\mathrm{TiO}_{2}$ films fabricated by sol-gel and spin coating have been investigated combining experiments and first-principles calculations. All the samples exhibit the anatase crystal phase and the room temperature ferromagnetism. The values of the saturation magnetizations are in the order of $\mathrm{Fe}-\mathrm{C}$ codoped $\mathrm{TiO}_{2}>\mathrm{Fe}-\mathrm{C}$ codoped $\mathrm{TiO}_{2}($ annealed in $\mathrm{O}_{2}$ ) > C doped $\mathrm{TiO}_{2}>\mathrm{C}$ doped $\mathrm{TiO}_{2}$ (annealed in $\mathrm{O}_{2}$ ). The calculated net moment values are in the order of Fe- $\mathrm{C}$ codoped $\mathrm{TiO}_{2}>\mathrm{C}$ doped $\mathrm{TiO}_{2}$ with oxygen vacancies existing, in accord with the experimental results. The hybridization of $\mathrm{Fe} 3 d, \mathrm{C} 2 p$, and $\mathrm{O} 2 p$ (nearest to the Fe defect) led to the spin split of $\mathrm{Fe} 3 d, \mathrm{C} 2 p$, and $\mathrm{O} 2 p$ which contributed to the ferromagnetism.

\section{Introduction}

Diluted magnetic semiconductors (DMSs) are promising candidates for the spin-polarized devices such as magnetooptical, nonvolatile storage and other spin logical devices [1]. However, most of these DMSs have relatively low Curie temperatures $\left(T_{C}\right)$, reducing their practical usefulness. In the recent decades, oxide diluted magnetic semiconductors such as $\mathrm{ZnO}$ [2], $\mathrm{SnO}_{2}$ [3], and $\mathrm{TiO}_{2}$ [4] doped with magnetic transition metal elements have attracted considerable attention, due to the discovery of room temperature (RT) ferromagnetism (FM) in these systems. Several theoretical investigations have been reported, most of which focus on the cation vacancies in $\mathrm{TiO}_{2}$ bulk materials [5-10]. However, recent studies showed that the unexpected RT FM is closely related to the oxygen vacancies (Vos) instead of the cation vacancies [11-17]. Vo is a type of defects in $\mathrm{TiO}_{2}$ which can be manipulated relatively easily during the synthesis processing [17]. Near the surface or in the bulk, Vos can lead to ferromagnetism enabling a possible application for $\mathrm{TiO}_{2}$ as a magnetic semiconductor in spintronics [18].

In $\mathrm{TiO}_{2}$ based DMSs, it is concluded that there are four factors related to the observed ferromagnetism: the Vos, cation vacancies, transition metal dopants, and the change of titanium oxidation state $\left(\mathrm{Ti}^{3+}\right)$ [16]. On the one hand, the Vos can cause an obvious change in the band structure and make a significant contribution to the FM. On the other hand, the transition metal elements which have unpaired d-electrons can provide magnetic moment to the DMSs. In this paper, we have investigated the electronic and magnetic properties of transition metal $(\mathrm{Fe})$, nonmetal $\mathrm{C}$, and Vos codoped anatase $\mathrm{TiO}_{2}\left(\mathrm{Ti}_{31} \mathrm{FeO}_{62} \mathrm{C}\right)$ combining the experiments and the first-principles calculations based on the density-functional theory (DFT). The experimental results are consistent with the first-principles calculations. The magnetism induced by the $\mathrm{Fe}$ and $\mathrm{C}(\mathrm{Fe}-\mathrm{C})$ codoping is investigated being associated with the $\mathrm{V}_{\mathrm{O}}$ defect electrons. The connections between doped $\mathrm{Fe}$ ions, $\mathrm{C}$ ions, and Vos are discussed to explain the ferromagnetism observed in these materials.

\section{Experiments and Calculations}

The $\mathrm{C}$ doped $\mathrm{TiO}_{2}$ films, $\mathrm{C}$ doped $\mathrm{TiO}_{2}$ films (annealed in $\mathrm{O}_{2}$ ), Fe-C codoped $\mathrm{TiO}_{2}$ films, and $\mathrm{Fe}-\mathrm{C}$ codoped $\mathrm{TiO}_{2}$ films (annealed in $\mathrm{O}_{2}$ ) were prepared by sol-gel and spincoating methods. A clear solution was prepared by reacting tetrabutyl titanate $\left(\mathrm{C}_{16} \mathrm{H}_{36} \mathrm{O}_{4} \mathrm{Ti}\right)$ and nanotube carbon $(\mathrm{C})$ with a mixture of water and hydrochloric acid $(\mathrm{HCl})$ in an 
ethanol $\left(\mathrm{C}_{2} \mathrm{H}_{5} \mathrm{OH}\right)$ diluted medium. The $\mathrm{C}$ doped $\mathrm{TiO}_{2}$ films were spin-coated on the fluorine doped tin oxide (FTO) substrates with the mentioned solution. After the prebaking at $70^{\circ} \mathrm{C}$ for $30 \mathrm{~min}$, these films were annealed at $450^{\circ} \mathrm{C}$ for $2 \mathrm{~h}$ in $\mathrm{O}_{2}$ gas and in air to obtain the $\mathrm{C}$ doped and the Vos-decreased $\mathrm{C}$ doped $\mathrm{TiO}_{2}$ films, respectively. To get the $\mathrm{Fe}-\mathrm{C}$ codoped samples, iron nitrate hydrate was added into deionized water; and the $\mathrm{C}$ doped $\mathrm{TiO}_{2}$ films were immersed in the solution for 1 hour. Following the same procedure as that for the $\mathrm{C}$ doped and the Vos-decreased $\mathrm{C}$ doped $\mathrm{TiO}_{2}$ samples, the Fe-C codoped and the Vos-decreased Fe-C codoped samples were prepared.

The crystal structures were characterized by X-ray diffraction (XRD, Bruker D8 Discover) with $\mathrm{Cu} \mathrm{K} \alpha$ radiation $(\lambda=1.54 \AA)$. The electronic structures were measured by the X-ray photoelectron spectroscopy (XPS) and the binding energy of the XPS spectra was calibrated with reference to the $\mathrm{C} 1 \mathrm{~s}$ peak at $284.6 \mathrm{eV}$. The optical absorption spectra in the wavelength range of $200-800 \mathrm{~nm}$ were measured by using ultraviolet-visible near infrared spectrophotometer (CARY5000, Varian) at RT under the diffuse reflection mode with the integrating sphere. The photoluminescence (PL) spectra were conducted by using the $325 \mathrm{~nm} \mathrm{He}-\mathrm{Cd}$ laser (20 MW) as an excitation light source. The magnetic properties were studied using a vibrating-sample magnetometer (VSM) equipped in the physical property measurement system (PPMS, Quantum Deign). The magnetization loops were recorded with the magnetic field from $-1 \mathrm{~T}$ to $1 \mathrm{~T}$ ( $\mathrm{T}$ is the abbreviation of Tesla) applied parallel to the samples surfaces.

First-principles calculations based on spin-polarized density-functional theory and projector augmented wave (PAW) pseudopotential technique are performed as implemented within the Vienna Ab-Initio Simulation Package (VASP) $[19,20]$. The generalized gradient approximation (GGA-PBE) for the wave functions is used with a cutoff of $400 \mathrm{eV}$ to model the exchange and correlation functional [21]. The calculations have been carried out for three cases: (1) one oxygen $(\mathrm{O})$ atom is substituted by a $\mathrm{Vo}\left(\mathrm{Ti}_{32} \mathrm{O}_{63}\right) ;(2)$ two $\mathrm{O}$ atoms are substituted by a Vo and a $\mathrm{C}$ atom $\left(\mathrm{Ti}_{32} \mathrm{O}_{62} \mathrm{C}\right) ;(3)$ a titanium (Ti) atom and two $\mathrm{O}$ atoms are substituted by an Fe atom, a $\mathrm{V}_{\mathrm{O}}$, and a $\mathrm{C}$ atom $\left(\mathrm{Ti}_{31} \mathrm{FeO}_{62} \mathrm{C}\right)$. The MonkhorstPack scheme $k$-points grid sampling was set to be $2 \times 2 \times$ 5 for the 95 -atom anatase supercell. The valence electrons configurations for the $\mathrm{O}, \mathrm{C}, \mathrm{Ti}$, and Fe are $2 \mathrm{~s}^{2} 2 \mathrm{p}^{4}, 2 \mathrm{~s}^{2} 2 \mathrm{p}^{2}, 3 \mathrm{~s}^{2}$ $3 \mathrm{p}^{6} 3 \mathrm{~d}^{2} 4 \mathrm{~s}^{2}$, and $3 \mathrm{~d}^{3} 4 \mathrm{~s}^{2}$, respectively. All the atomic positions are fully optimized until the atom forces drop below the value $0.02 \mathrm{eV} / \AA$.

\section{Results and Discussions}

Figure 1 exhibits the XRD patterns of the $\mathrm{C}$ doped $\mathrm{TiO}_{2}$ films, $\mathrm{C}$ doped $\mathrm{TiO}_{2}$ films (annealed in $\mathrm{O}_{2}$ ), Fe-C codoped $\mathrm{TiO}_{2}$ films, and Fe-C codoped $\mathrm{TiO}_{2}$ films (annealed in $\mathrm{O}_{2}$ ). It can be seen that the XRD diffraction peaks of the undoped $\mathrm{TiO}_{2}$ film appearing around $25.3^{\circ}, 36.9^{\circ}, 37.8^{\circ}, 38.5^{\circ}, 48.0^{\circ}, 53.9^{\circ}$, $55.0^{\circ}, 62.1^{\circ}, 62.6^{\circ}, 68.7^{\circ}, 70.2^{\circ}$, and $75.0^{\circ}$ are indexed to (101), (103), (004), (112), (200), (105), (211), (213), (204), (116), (220), and (215) of the anatase phase (JCPDS, number 21-1272); and the XRD diffraction peaks at $26.7^{\circ}, 34.0^{\circ}, 51.7^{\circ}$, and $65.8^{\circ}$ are

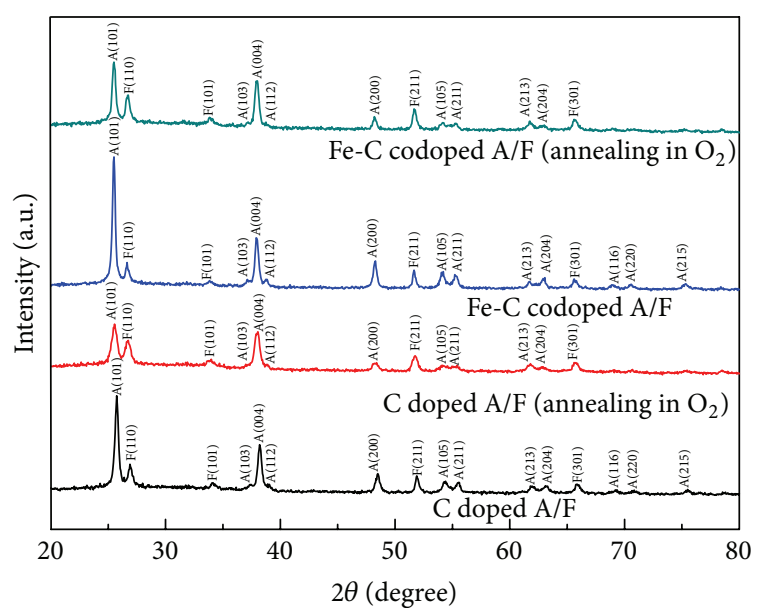

FIGURE 1: XRD patterns of the C doped A/F films, C doped A/F films (annealed in $\mathrm{O}_{2}$ ), Fe-C codoped A/F films, and Fe-C codoped A/F films (annealed in $\mathrm{O}_{2}$ ) on FTO substrates (A/F; A: anatase; F: ITO).

referred to as FTO (110), (101), (211), and (301). No signals of impurities such as rutile, $\mathrm{FeTiO}_{3}$, or Fe cluster are detected. In addition, for the $\mathrm{C}$ doped $\mathrm{TiO}_{2}$ films (annealed in $\mathrm{O}_{2}$ ) and $\mathrm{Fe}$ $\mathrm{C}$ codoped $\mathrm{TiO}_{2}$ films (annealed in $\mathrm{O}_{2}$ ), the XRD diffraction peaks show a relative lower intensity and a wider full width at half maximum (FWHM) comparing with the XRD data of C doped $\mathrm{TiO}_{2}$ films and $\mathrm{Fe}-\mathrm{C}$ codoped $\mathrm{TiO}_{2}$ films. The average particle sizes of all the films were calculated and estimated using Scherrer equation choosing the Brag angle at (101), (004), and (200) diffraction peak. It is shown that the values of average particle size are $24.5 \mathrm{~nm}$ and $26.8 \mathrm{~nm}$, for the C doped $\mathrm{TiO}_{2}$ films and $\mathrm{Fe}-\mathrm{C}$ codoped $\mathrm{TiO}_{2}$ films, respectively. After the sample was annealed in $\mathrm{O}_{2}$ gas, the values of average particle size decreased to $18.2 \mathrm{~nm}$ and $23.6 \mathrm{~nm}$ for the $\mathrm{C}$ doped $\mathrm{TiO}_{2}$ films and $\mathrm{Fe}-\mathrm{C}$ codoped $\mathrm{TiO}_{2}$ films. The variation of the particle size originates from the difference of the doped element $(\mathrm{Fe}$ or $\mathrm{C})$ and annealing gas $\left(\mathrm{O}_{2}\right)$.

Figure 2 demonstrates the XPS core levels for O-1s, C$1 s$, and $\mathrm{Fe}-2 \mathrm{p}$ of the $\mathrm{Fe}-\mathrm{C}$ codoped $\mathrm{TiO}_{2}$ films. As it is shown in Figure 2(a), the core level spectrum of O-1s is fitted with two peaks at $530.14 \mathrm{eV}$ and $531.70 \mathrm{eV}$, attributed to $\mathrm{O}$ 1s in Ti-O linkages and $\mathrm{Ti}-\mathrm{O}-\mathrm{C}$ bonds of $\mathrm{TiO}_{2}$, respectively. Figure 2(b) shows the core level spectrum of C-1s which can be fitted by four peaks at $284.84 \mathrm{eV}, 286.71 \mathrm{eV}, 283.6 \mathrm{eV}$, and $288.60 \mathrm{eV}$, respectively. The peak of $284.84 \mathrm{eV}$ clearly arises from adventitious element carbon which also exists in the case of pure $\mathrm{TiO}_{2}$ samples. The peaks at $286.71 \mathrm{eV}, 283.6 \mathrm{eV}$, and $288.60 \mathrm{eV}$ are attributed to $\mathrm{C}-\mathrm{O}$ and $\mathrm{C}-\mathrm{Ti}$ and $\mathrm{COOH}$ binding, respectively. Therefore, multiple carbon species, namely, substitutional and interstitial carbon atoms and carbonate species, coexist in the lattice of $\mathrm{TiO}_{2}$. Figure 2(c) reveals the Fe $2 p$ core level XPS spectrum. Apparently, there are two main peaks of $\mathrm{Fe} 2 \mathrm{p}_{3 / 2}$ and $\mathrm{Fe} 2 \mathrm{p}_{1 / 2}$ located at $710.71 \mathrm{eV}$ and $724.52 \mathrm{eV}$, respectively, close to the binding energy of $\mathrm{Fe}^{3+}$ ion which indicates the existence of $\mathrm{Fe}^{3+}$ [22]. It is noticed that there is no weak peak at binding energy around $709 \mathrm{eV}$ introduced by the contribution of $\mathrm{Fe}^{2+}$ ion in the spectrum. 


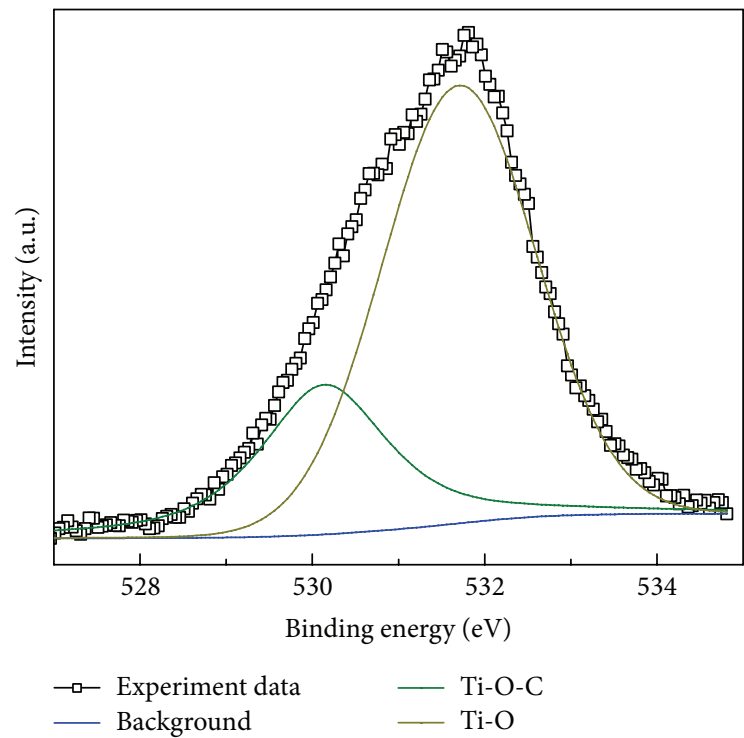

(a)

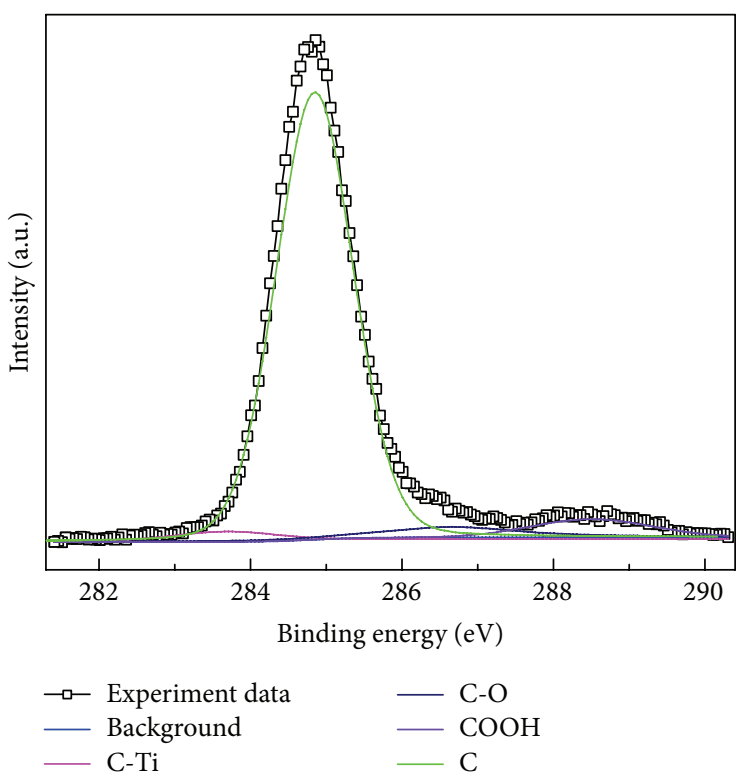

(b)

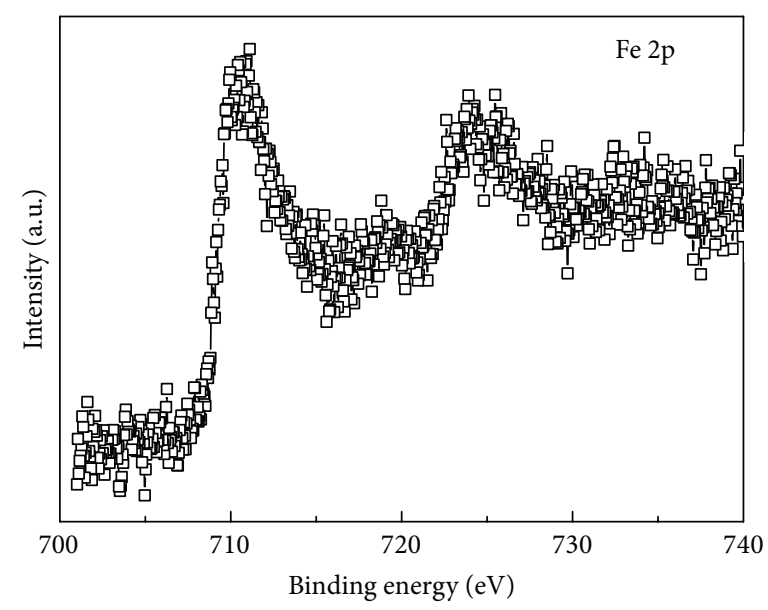

(c)

Figure 2: XPS of core level signals of (a) O1s, (b) C 1s, and (c) Fe 2p of the Fe-C codoped $\mathrm{TiO}_{2}$.

Figure 3(a) illustrates the UV-Vis absorption spectra for these samples, which exhibit the characteristic spectrum of $\mathrm{TiO}_{2}$ with its fundamental absorption edge around $384 \mathrm{~nm}$ (3.2 $\mathrm{eV}$ of band-gap energy). The absorption edges of the $\mathrm{C}$ doped $\mathrm{TiO}_{2}$ films, C doped $\mathrm{TiO}_{2}$ films (annealed in $\mathrm{O}_{2}$ ), Fe-C codoped $\mathrm{TiO}_{2}$ films, and $\mathrm{Fe}-\mathrm{C}$ codoped $\mathrm{TiO}_{2}$ films (annealed in $\mathrm{O}_{2}$ ) are $387 \mathrm{~nm}, 370 \mathrm{~nm}, 399 \mathrm{~nm}$, and $392 \mathrm{~nm}$, with calculated band-gap energy of $3.20 \mathrm{eV}, 3.35 \mathrm{eV}, 3.11 \mathrm{eV}$, and $3.16 \mathrm{eV}$, respectively, similar to those reported in $[23,24]$. Comparing with the samples annealed in $\mathrm{O}_{2}$ atmosphere, the absorption edges of the $\mathrm{C}$ doped and $\mathrm{Fe}-\mathrm{C}$ codoped $\mathrm{TiO}_{2}$ films both shifted slightly toward the visible light range. The values of the band gap are in the following order: $\mathrm{Fe}-\mathrm{C}$ codoped $\mathrm{TiO}_{2}>$ Fe-C codoped $\mathrm{TiO}_{2}$ (annealing in $\mathrm{O}_{2}$ ) $>\mathrm{C}$ doped $\mathrm{TiO}_{2}>$ $\mathrm{C}$ doped $\mathrm{TiO}_{2}$ (annealing in $\mathrm{O}_{2}$ ). The spectrum of Fe-C codoped sample yields the largest red shift which indicates the doping of $\mathrm{Fe}$ or $\mathrm{C}$ element may narrow the band gap.
Figure 3(b) presents the PL spectra of C doped $\mathrm{TiO}_{2}$ films, $\mathrm{C}$ doped $\mathrm{TiO}_{2}$ films (annealing in $\mathrm{O}_{2}$ ), $\mathrm{Fe}-\mathrm{C}$ codoped $\mathrm{TiO}_{2}$ films, and $\mathrm{Fe}-\mathrm{C}$ codoped $\mathrm{TiO}_{2}$ films (annealing in $\mathrm{O}_{2}$ ) at RT. The PL spectra are very sensitive to the stoichiometry and surface states for materials, which can provide information on electronic and optical properties $[25,26]$. All the PL spectra of the specimens show two strong emission peaks at $468 \mathrm{~nm}$ and $480 \mathrm{~nm}$, which are attributed to the Vos $[27,28]$. The emission peaks corresponding to the defects are largely enhanced after annealing in $\mathrm{O}_{2}$ gas.

Figure 4 shows the plots of magnetization $(M)$ versus applied magnetic field $(H)$ which demonstrate hysteresis behaviour in all samples measured by a VSM with the magnetic field from -1 to $1 \mathrm{~T}$ at RT. The values of the saturation magnetization $\left(M_{s}\right)$ are in the following order: the $\mathrm{C}$ doped $\mathrm{TiO}_{2}$ (annealed in $\mathrm{O}_{2}$ ) $<\mathrm{C}$ doped $\mathrm{TiO}_{2}<\mathrm{Fe}-\mathrm{C}$ codoped $\mathrm{TiO}_{2}$ (annealed in $\mathrm{O}_{2}$ ) $<$ Fe-C codoped $\mathrm{TiO}_{2}$. 


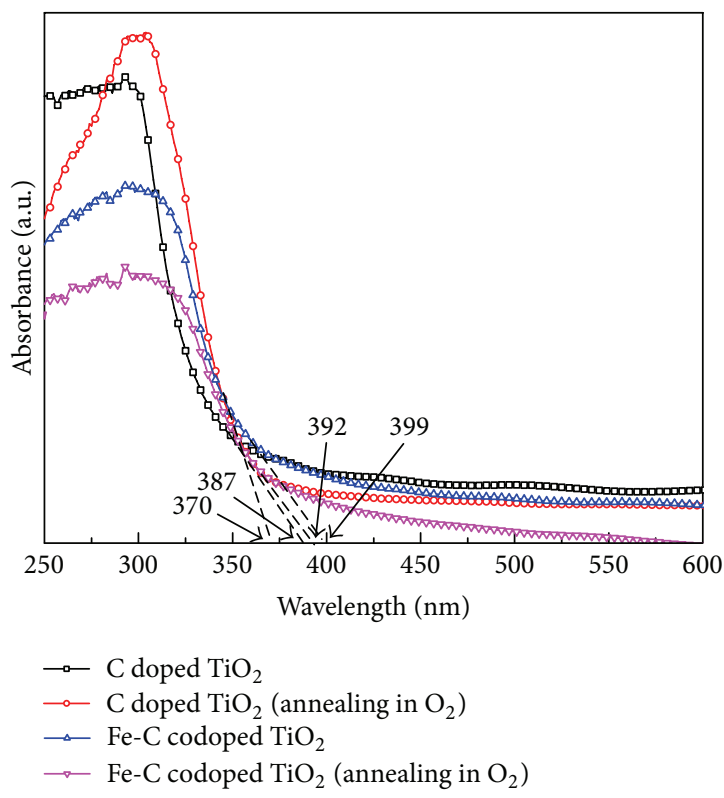

(a)

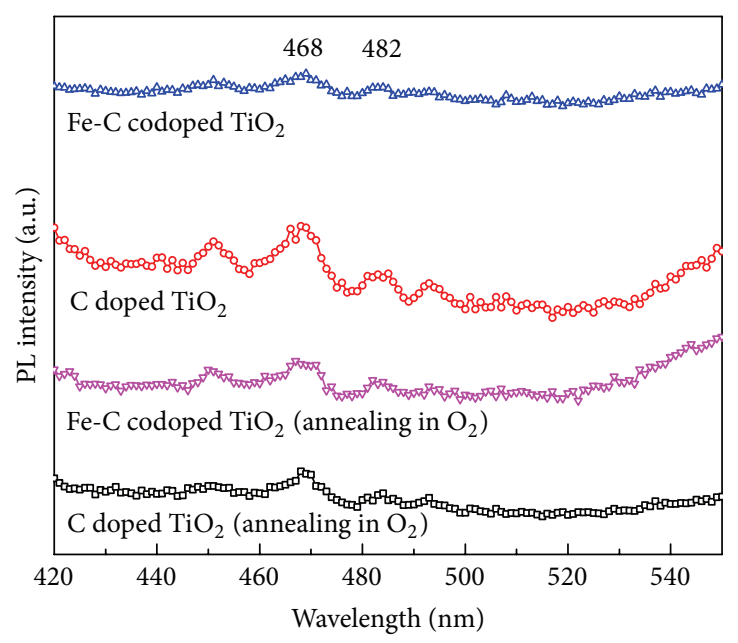

(b)

Figure 3: (a) The UV-Vis spectra and (b) PL spectra of the $\mathrm{C}$ doped $\mathrm{TiO}_{2}$ films, $\mathrm{C}$ doped $\mathrm{TiO}_{2}$ films (annealing in $\mathrm{O}_{2}$ ), $\mathrm{Fe}-\mathrm{C}$ codoped $\mathrm{TiO}{ }_{2}$ films, and $\mathrm{Fe}-\mathrm{C}$ codoped $\mathrm{TiO}_{2}$ films (annealing in $\mathrm{O}_{2}$ ).

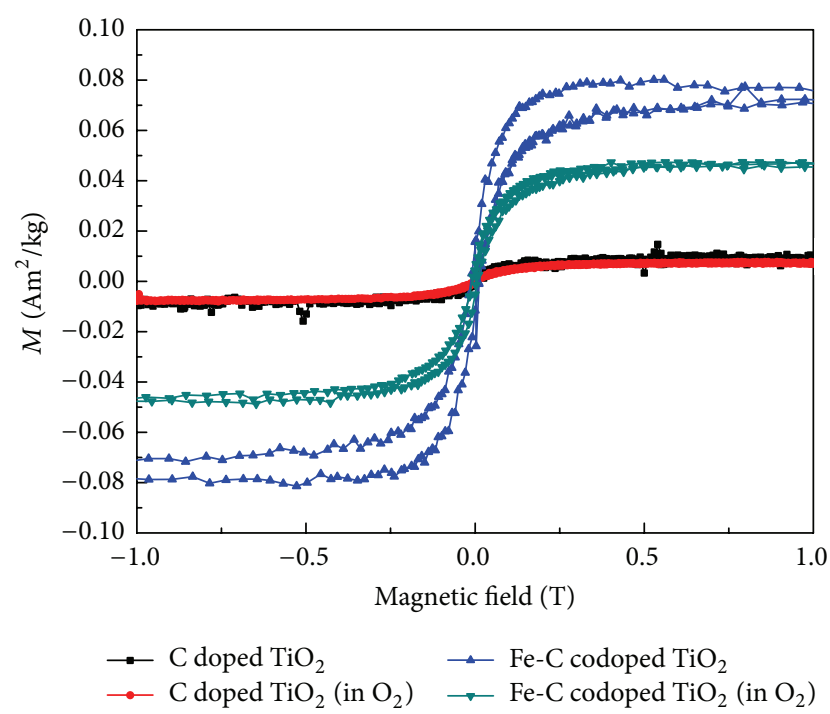

Figure 4: Hysteresis loops of the $\mathrm{C}$ doped $\mathrm{TiO}_{2}$ films, $\mathrm{C}$ doped $\mathrm{TiO}_{2}$ films (annealed in $\mathrm{O}_{2}$ ), Fe-C codoped $\mathrm{TiO}_{2}$ films, and $\mathrm{Fe}-\mathrm{C}$ codoped $\mathrm{TiO}_{2}$ films (annealed in $\mathrm{O}_{2}$ ) at RT.

In order to understand the origin of RT FM in the Fe$\mathrm{C}$ codoped $\mathrm{TiO}_{2}$ films, the first-principles calculations are performed. The positions of $\mathrm{V}_{\mathrm{O}}, \mathrm{Ti}, \mathrm{Fe}, \mathrm{C}$, and $\mathrm{O}$ for $\mathrm{V}_{\mathrm{O}^{-}}$ Fe-C codoped $\mathrm{TiO}_{2}$ are the same as those of the $\mathrm{V}_{\mathrm{O}}$ doped $\mathrm{TiO}_{2}$ and the $\mathrm{V}_{\mathrm{O}}-\mathrm{C}$ codoped $\mathrm{TiO}_{2}$. Firstly, when there exists only one Vo in the supercell, each Vo is assumed to donate two electrons. The result indicates that the two electrons created by one Vo are shared by three equivalent $\mathrm{Ti}^{3+}$ ions with up-spin of three different directions, which is similar to the results reported by Yang et al. [29]. The calculated net magnetic moment of the system is about $0.533 \mu_{B}$, which is related to the denoted two electrons that occupy the three neighboring Ti sites. The second and the third scenarios are $\mathrm{V}_{\mathrm{O}}-\mathrm{C}$ codoped $\mathrm{TiO}_{2}\left(\mathrm{Ti}_{32} \mathrm{O}_{62} \mathrm{C}\right)$ and $\mathrm{V}_{\mathrm{O}}$-Fe-C codoped $\mathrm{TiO}_{2}$ $\left(\mathrm{Ti}_{31} \mathrm{FeO}_{62} \mathrm{C}\right)$, respectively.

Figure 5 shows the TDOS and PDOS of Vo-C codoped $\mathrm{TiO}_{2}$ and $\mathrm{Vo}-\mathrm{Fe}-\mathrm{C}$ codoped $\mathrm{TiO}_{2}$, respectively. The calculated band gaps using the GGA functional are about $2.09 \mathrm{eV}$ for the Vo-C codoped $\mathrm{TiO}_{2}$ and $\mathrm{Vo}-\mathrm{Fe}-\mathrm{C}$ codoped $\mathrm{TiO}_{2}$, which is lower than the experimental value of $3.20 \mathrm{eV}$. However, the reduced band gap has nearly no influence on the magnetic state of $\mathrm{C}$ doped anatase $\mathrm{TiO}_{2}$ and $\mathrm{Fe}-\mathrm{C}$ codoped $\mathrm{TiO}_{2}$.

Figure 5(a) shows the TDOS and PDOS of C $2 p$ electrons for Vo-C codoped $\mathrm{TiO}_{2}$ samples. It can be seen from Figure 5(a)I that there is no spin splitting around the Fermi level, which illustrates that the Vo-C codoped $\mathrm{TiO}_{2}$ samples have no magnetic property. For the PDOS of C $2 p$ electrons (in Figure 5(a)II) nearest to the Vo, there are also no exchange splitting around the Fermi level between the spin-up and spin-down states, lying within the band gap. With respect to the local Cartesian coordinate, the up-spin and downspin of C $2 p_{x}, \mathrm{C} 2 p_{y}$, and C $2 p_{z}$ states are all occupied. This indicates that the two electrons, created by one Vo, were trapped by the doped $\mathrm{C}$ atom. As a result, the valence electrons configuration for doped $C$ atom is $1 s^{2} 2 p^{6}$, which produces $0 \mu_{B}$ net magnetic moment.

Figure 5(b)I exhibits the TDOS for Vo-Fe-C codoped $\mathrm{TiO}_{2}$ sample. It can be seen that a part splitting between the spin-up and spin-down states around the Fermi level is shown illustrating the existence of magnetism. For the PDOS of Fe $3 d$ electrons (in Figure 5(b)II), the Fe $3 d$ states are spin-polarized and lie within the band gap of Vo-Fe-C 

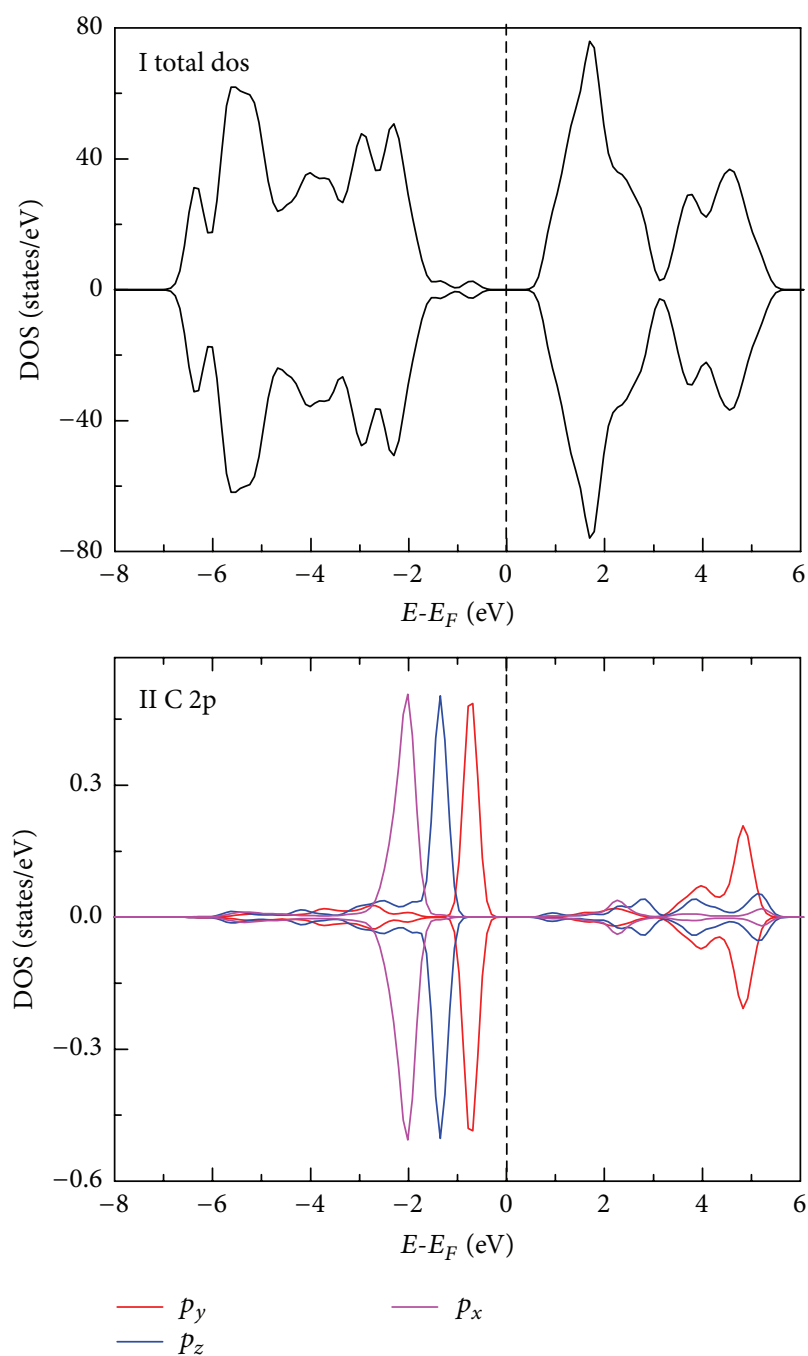

(a)
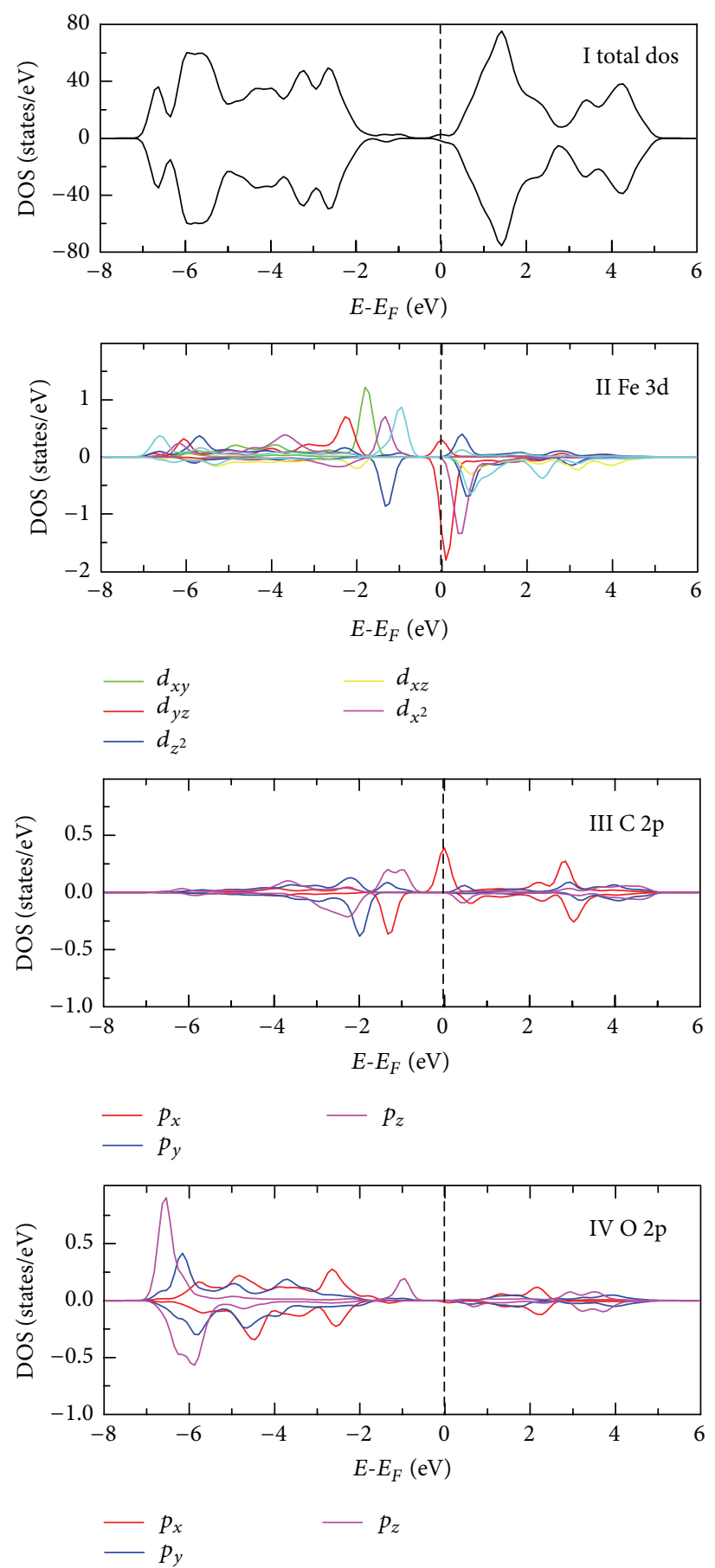

(b)

FIgure 5: TDOS and PDOS for (a) $\mathrm{V}_{\mathrm{O}}-\mathrm{C}$ codoped $\mathrm{TiO}_{2}$ and (b) $\mathrm{V}_{\mathrm{O}}-\mathrm{Fe}-\mathrm{C}$ codoped $\mathrm{TiO}_{2}$.

codoped $\mathrm{TiO}_{2}$. With respect to the local Cartesian coordinate, the spin-up and spin-down states of Fe $3 d_{y z}$ are occupied, while for $\mathrm{Fe} 3 d_{x y}$, Fe $3 d_{x z}$, and $\mathrm{Fe} 3 d_{x^{2}}$ the spin-up states are occupied; for Fe $3 d_{x y}$, only a few spin-down states are occupied. Noticeably, there are no spin-up and spin-down states of $\mathrm{Fe} 3 d_{z^{2}}$ occupied. This indicates that each doped $\mathrm{Fe}$ atom at the Ti site produces the net magnetic moments of $2.538 \mu_{B}$, and its electron configuration can be resembled as
$\mathrm{Fe}^{3+}\left(3 d^{5}\right)$. For the PDOS of C 2p electrons (in Figure 5(b)III), the $\mathrm{C} 2 p$ states are spin-polarized and lie within the band gap of Vo-Fe-C codoped $\mathrm{TiO}_{2}$. With respect to the local Cartesian coordinate, the spin-up and spin-down states of C $2 p_{y}$ and C $2 p_{z}$ are all occupied, while, for C $2 p_{x}$, the spin-down C $2 p_{x}$ states are occupied and partly spin-up $2 p_{x}$ states are not; as a result, the valence electrons configuration for the doped $\mathrm{C}$ atom is $1 \mathrm{~s}^{2} 2 \mathrm{p}^{5}$. This indicates that each doped $\mathrm{C}$ atom at 
the $\mathrm{O}$ site produces $-0.025 \mu_{B}$ net magnetic moments. For the PDOS of $\mathrm{O} 2 p$ electrons (in Figure 5(b)IV), the C $2 p$ states are partly spin-polarized and lie within the band gap of Vo-Fe-C codoped $\mathrm{TiO}_{2}$. With respect to the local Cartesian coordinate, the spin-up and spin-down states of $\mathrm{O} 2 p_{x}, \mathrm{O} 2 p_{y}$, and $\mathrm{C}$ $2 p_{z}$ are all occupied, but the slightly spin-up states of $\mathrm{O} 2 p_{z}$ appear around Fermi level energy; as a result, the valence electrons configuration for $\mathrm{O}$ atom is $1 s^{2} 2 \mathrm{p}^{6}$. The calculated net magnetic moment of $\mathrm{O}$ atom nearest to doped $\mathrm{Fe}$ atom is $0.075 \mu_{B}$.

To analyze the spin polarization induced by the doped Fe atom and $\mathrm{C}$ atom, we calculated the spin density distribution $\mathrm{Fe}$ and $\mathrm{C}$ atom. The calculated results are that the magnetic moment is mainly delocalized around the Fe atom, namely, about $2.538 \mu_{B}$ on the Fe atom, about $-0.025 \mu_{B}$ on the $\mathrm{C}$ atom, about $0.079 \mu_{B}$ on the nearest-neighbor $\mathrm{O}$ atom, and about $0.029 \mu_{B}$ on the second-neighbor $\mathrm{O}$ atom. The calculated result indicates that the magnetic orbital describing the doped $\mathrm{Fe}$, Vo, and $\mathrm{C}$ center extends to the second-nearest-neighbor $\mathrm{O}$ atoms. One of the two electrons created by the Vo is trapped by the doped $\mathrm{C}$ atom, and the other one is shared by $\mathrm{Fe}, \mathrm{C}$, and $\mathrm{O}$ atoms surrounding it. The total magnetic moment is $3.216 \mu_{B}$ for the Vo-Fe-C codoped $\mathrm{TiO}_{2}$.

Combining all the results presented above, we introduced a defect electron based model for the observed ferromagnetism. The magnetic moment is associated with a Vo, $\mathrm{C}^{2-} / \mathrm{Vo} / \mathrm{Ti}^{4+}$, and $\mathrm{C}^{2-} / \mathrm{Fe}^{3+} / \mathrm{Vo}$ complex for $\mathrm{Vo}-\mathrm{C}$ codoped $\mathrm{TiO}_{2}$ and $\mathrm{Vo}-\mathrm{Fe}-\mathrm{C}$ codoped $\mathrm{TiO}_{2}$, respectively. The magnetic orbitals extend to nearest neighbor and second neighbor around the complex. In the two models, the two electrons denoted by $\mathrm{Vo}$ mediate the coupling of $\mathrm{C}^{2-} / \mathrm{Vo} / \mathrm{Ti}^{4+}$ and $\mathrm{C}^{2-} / \mathrm{Fe}^{3+} / \mathrm{Vo}$ complex, possessing the characteristics of $3 d$ electrons of $\mathrm{Ti}^{4+}$ and $\mathrm{Fe}^{3+}$, occupying $\mathrm{C} 2 p$ site, partly $\mathrm{O} 2 p$ sites, and $\mathrm{Fe}^{3+}$ site. This is the original signal of the $\mathrm{C}^{2-}$ and $\mathrm{Fe}^{3+}$, which also can be used to explain the reason that there is only $\mathrm{Ti}^{4+}$ signal appearing in XPS spectra. The value of total magnetic moment for $\mathrm{Vo}-\mathrm{Fe}-\mathrm{C}$ codoped $\mathrm{TiO}_{2}$ and $\mathrm{Vo}-$ $\mathrm{C}$ doped $\mathrm{TiO}_{2}$ is in the same order of $M_{s}$ for $\mathrm{Fe}-\mathrm{C}$ codoped $\mathrm{TiO}_{2}$ and $\mathrm{C}$ doped $\mathrm{TiO}_{2}$.

\section{Conclusions}

In summary, the RT FM properties of the $\mathrm{C}$ doped $\mathrm{TiO}_{2}$ films and $\mathrm{Fe}-\mathrm{C}$ codoped $\mathrm{TiO}_{2}$ films have been investigated. The values of the saturation magnetizations are in the order of $\mathrm{Fe}-\mathrm{C}$ codoped $\mathrm{TiO}_{2}>\mathrm{Fe}-\mathrm{C}$ codoped $\mathrm{TiO}_{2}$ (annealed in $\mathrm{O}_{2}$ ) $>\mathrm{C}$ doped $\mathrm{TiO}_{2}>\mathrm{C}$ doped $\mathrm{TiO}_{2}$ films (annealed in $\mathrm{O}_{2}$ ). The calculated net moment values are in the order of Fe-C codoped $\mathrm{TiO}_{2}>\mathrm{C}$ doped $\mathrm{TiO}_{2}$ with Vos existing, which are in accord with the experimental results. These calculations suggest the key factor for the formation of ferromagnetic ordering is the Vo which contributes two electrons to the doped $\mathrm{C}$ atom and neighboring $\mathrm{O}$ sites. The hybridization of Fe $3 d, \mathrm{C} 2 p$ (nearest to the Fe atom), and $\mathrm{O} 2 p$ (nearest to the Fe defect) led to the spin splitting of $\mathrm{Fe} 3 d, \mathrm{C} 2 p$, and $\mathrm{O} 2 p$ which contributed to the magnetism. The unique characteristic of the defect electrons denoted by a Vo in Fe$\mathrm{C}$ codoped $\mathrm{TiO}_{2}$ and $\mathrm{C}$ doped $\mathrm{TiO}_{2}$ is that they provide the means for the percolation of the magnetic complexes to achieve magnetization in the $\mathrm{Fe}-\mathrm{C}$ codoped samples.

\section{Competing Interests}

The authors declare that there is no conflict of interests regarding the publication of this paper.

\section{Acknowledgments}

This work is supported by the NSFC nos. 11404100, 11175135, 10904116, and 11304083, the Key Scientific and Technological Project of Henan Province no. 102102210186, the Postdoctoral Research Foundation of Henan Normal University no. 01026500204, and the Scientific Research Foundation for Ph.D. of Henan Normal University nos. 01026500257 and 01026500121. This work is also supported by the High Performance Computing Center of Henan Normal University.

\section{References}

[1] B. Pal and P. K. Giri, "High temperature ferromagnetism and optical properties of Co doped $\mathrm{ZnO}$ nanoparticles," Journal of Applied Physics, vol. 108, no. 8, Article ID 084322, 2010.

[2] K. Ueda, H. Tabata, and T. Kawai, "Magnetic and electric properties of transition-metal-doped $\mathrm{ZnO}$ films," Applied Physics Letters, vol. 79, no. 7, pp. 988-990, 2001.

[3] X. Liu, J. Iqbal, Z. Wu, B. He, and R. Yu, "Structure and roomtemperature ferromagnetism of $\mathrm{Zn}$-doped $\mathrm{SnO}_{2}$ nanorods prepared by solvothermal method," The Journal of Physical Chemistry C, vol. 114, no. 11, pp. 4790-4796, 2010.

[4] R. K. Singhal, A. Samariya, S. Kumar et al., "Study of defectinduced ferromagnetism in hydrogenated anatase $\mathrm{TiO}_{2}: \mathrm{Co}$," Journal of Applied Physics, vol. 107, no. 11, Article ID 113916, 2010.

[5] Y. Bai and Q. Chen, "First principle study of the cation vacancy in anatase $\mathrm{TiO}_{2}$," Physica Status Solidi-Rapid Research Letters, vol. 2, no. 1, pp. 25-27, 2008.

[6] H. Peng, J. Li, S.-S. Li, and J.-B. Xia, "Possible origin of ferromagnetism in undoped anatase $\mathrm{TiO}_{2}$," Physical Review BCondensed Matter and Materials Physics, vol. 79, no. 9, Article ID 092411, 4 pages, 2009.

[7] N. Yu and J. W. Halley, "Electronic structure of point defects in rutile $\mathrm{TiO}_{2}$," Physical Review B, vol. 51, no. 8, pp. 4768-4776, 1995.

[8] E. Cho, S. Han, H.-S. Ahn, K.-R. Lee, S. K. Kim, and C. S. Hwang, "First-principles study of point defects in rutile $\mathrm{TiO}_{2-x}$ ", Physical Review B, vol. 73, no. 19, Article ID 193202, 2006.

[9] S.-G. Park, B. Magyari-Köpe, and Y. Nishi, "Electronic correlation effects in reduced rutile $\mathrm{TiO}_{2}$ within the $\mathrm{LDA}+\mathrm{U}$ method," Physical Review B, vol. 82, no. 11, Article ID 115109, 2010.

[10] M. Setvin, C. Franchini, X. Hao et al., "Direct view at excess electrons in $\mathrm{TiO}_{2}$ rutile and anatase," Physical Review Letters, vol. 113, no. 8, Article ID 086402, 5 pages, 2014.

[11] M. Wang, M. Feng, and X. Zuo, "First principles study of the electronic structure and magnetism of oxygen-deficient anatase $\mathrm{TiO}_{2}\left(\begin{array}{ll}0 & 0\end{array}\right)$ surface," Applied Surface Science, vol. 292, no. 4, pp. 475-479, 2014

[12] Z. Zhou, H. Wang, and Z. Yang, "Intrinsic defect-mediated magnetism in $\mathrm{Fe}-\mathrm{N}$ codoped $\mathrm{TiO}_{2}$," Journal of Alloys and Compounds, vol. 657, pp. 372-378, 2016. 
[13] A. T. Brant, N. C. Giles, S. Yang et al., "Ground state of the singly ionized oxygen vacancy in rutile $\mathrm{TiO}_{2}$," Journal of Applied Physics, vol. 114, no. 11, Article ID 113702, 2013.

[14] A. M. M. Navarro, C. E. R. Torres, V. Bilovol, A. F. Cabrera, L. A. Errico, and M. Weissmann, "Study of the relation between oxygen vacancies and ferromagnetism in $\mathrm{Fe}$-doped $\mathrm{TiO}_{2}$ nanopowders," Journal of Applied Physics, vol. 115, no. 22, Article ID 223908, 2014.

[15] B. Shao, Y.-F. He, M. Feng, Y. Lu, and X. Zuo, "Unexpected magnetic anisotropy induced by oxygen vacancy in anatase $\mathrm{TiO}_{2}$ : a first-principles study," Journal of Applied Physics, vol. 115, no. 17, Article ID 17A915, 2014.

[16] X. J. Wang, Y. L. Song, L. L. Tao et al., "Origin of ferromagnetism in aluminum-doped $\mathrm{TiO}_{2}$ thin films: theory and experiments," Applied Physics Letters, vol. 105, no. 26, Article ID 262402, 2014.

[17] C. Lin, D. Shin, and A. A. Demkov, "Localized states induced by an oxygen vacancy in rutile $\mathrm{TiO}_{2}$," Journal of Applied Physics, vol. 117, no. 22, Article ID 225703, 2015.

[18] R. Janisch, P. Gopal, and N. A. Spaldin, "Transition metal-doped $\mathrm{TiO}_{2}$ and $\mathrm{ZnO}$ - present status of the field," Journal of Physics: Condensed Matter, vol. 17, no. 27, pp. R657-R689, 2005.

[19] G. Kresse and D. Joubert, "From ultrasoft pseudopotentials to the projector augmented-wave method," Physical Review B, vol. 59, no. 3, pp. $1758-1775,1999$.

[20] G. Kresse and J. Furthmüller, "Efficient iterative schemes for $a b$ initio total-energy calculations using a plane-wave basis set," Physical Review B-Condensed Matter and Materials Physics, vol. 54, no. 16, pp. 11169-11186, 1996.

[21] J. P. Perdew, K. Burke, and M. Ernzerhof, "Generalized gradient approximation made simple," Physical Review Letters, vol. 77, no. 18 , pp. 3865-3868, 1996.

[22] C. D. Wagner, W. M. Riggs, L. E. Davis, and J. F. Moulder, G.E. Muilenberg, editor, Perkin Elmer Corporation (Physical Electronics Division), Eden Prairie, Minn, USA, 1979.

[23] J. Yu, Q. Xiang, and M. Zhou, "Preparation, characterization and visible-light-driven photocatalytic activity of Fe-doped titania nanorods and first-principles study for electronic structures," Applied Catalysis B: Environmental, vol. 90, no. 3-4, pp. 595-602, 2009

[24] W. Choi, A. Termin, and M. R. Hoffmann, "The role of metal-ion dopants in quantum-sized $\mathrm{TiO}_{2}$ : correlation between photoreactivity and charge-carrier recombination dynamics," Journal of Physical Chemistry, vol. 98, no. 51, pp. 13669-13679, 1994.

[25] Y. Lei, L. D. Zhang, G. W. Meng et al., "Preparation and photoluminescence of highly ordered $\mathrm{TiO}_{2}$ nanowire arrays," Applied Physics Letters, vol. 78, no. 8, pp. 1125-1127, 2001.

[26] C. Huang, X. Liu, L. Kong, W. Lan, Q. Su, and Y. Wang, "The structural and magnetic properties of Co-doped titanate nanotubes synthesized under hydrothermal conditions," Applied Physics A: Materials Science and Processing, vol. 87, no. 4, pp. 781-786, 2007.

[27] J. H. Cho, B. Y. Kim, H. D. Kim et al., "Enhanced ferromagnetism in Co-doped $\mathrm{TiO}_{2}$ powders," Physica Status Solidi B: Basic Research, vol. 241, no. 7, pp. 1537-1540, 2004.

[28] P. M. Kumar, S. Badrinarayanan, and M. Sastry, "Nanocrystalline $\mathrm{TiO}_{2}$ studied by optical, FTIR and X-ray photoelectron spectroscopy: correlation to presence of surface states," Thin Solid Films, vol. 358, no. 1-2, pp. 122-130, 2000.

[29] K. Yang, Y. Dai, B. Huang, and Y. P. Feng, "Density-functional characterization of antiferromagnetism in oxygen-deficient anatase and rutile $\mathrm{TiO}_{2}$," Physical Review B-Condensed Matter and Materials Physics, vol. 81, no. 3, Article ID 033202, 2010. 

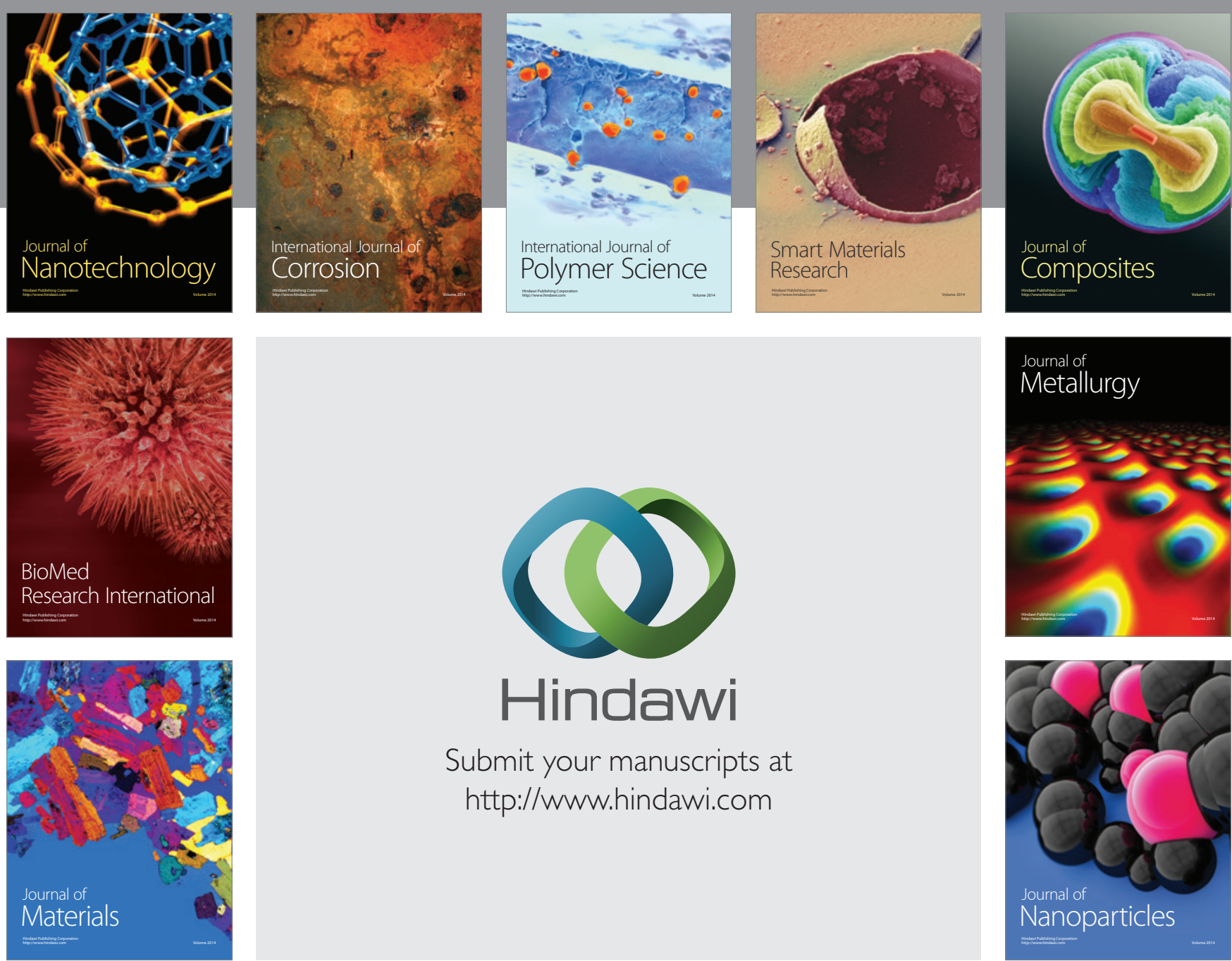

\section{Hindawi}

Submit your manuscripts at

http://www.hindawi.com

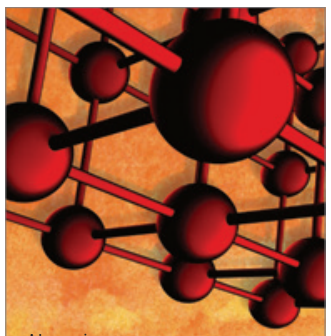

Materials Science and Engineering
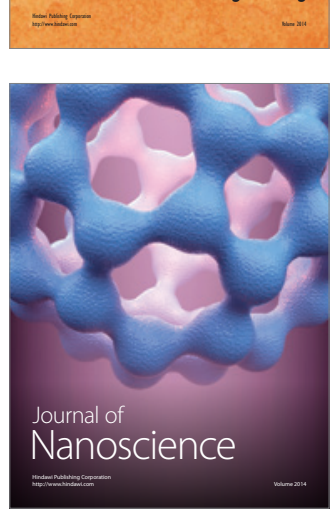
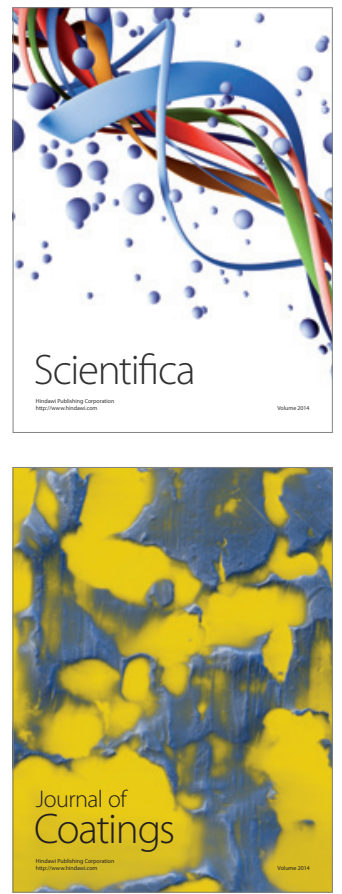
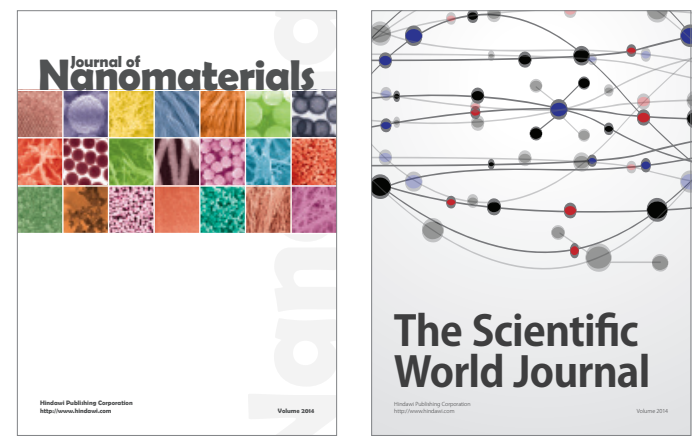

The Scientific World Journal
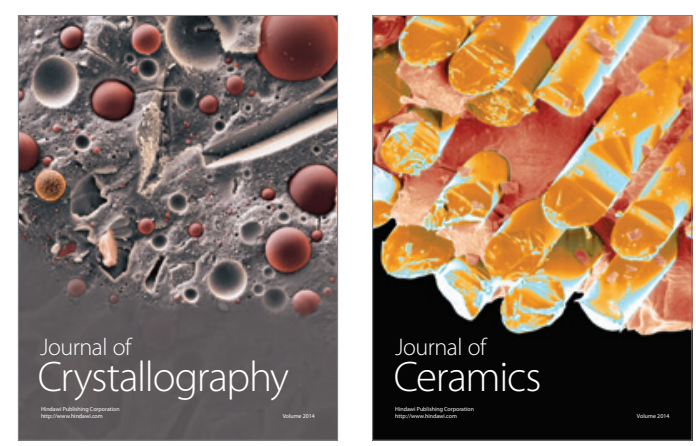
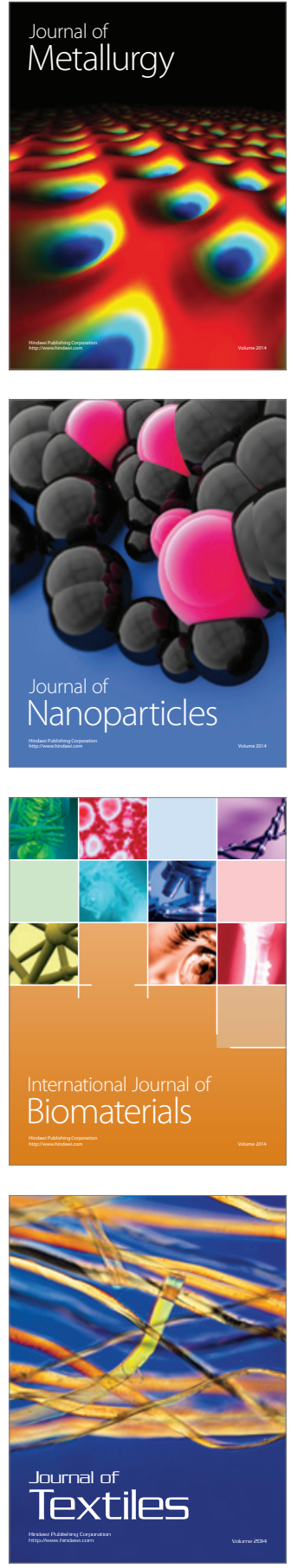